\title{
Developmental Evidence of Male and Female Gametophytes of Jatropha curcas L.: Pollen Capability and Stigma Receptivity
}

\author{
Nilubol NUANJUNKONG ${ }^{1, *}$, Chakrit TONGURAI $^{2}$ and Upatham MEESAWAT ${ }^{1}$ \\ ${ }^{1}$ Department of Biology, Faculty of Science, Prince of Songkla University, Songkhla 90110, Thailand \\ ${ }^{2}$ Department of Chemical Engineering, Faculty of Engineering, Prince of Songkla University, \\ Songkhla 90110, Thailand
}

('Corresponding author's e-mail: auey_orchid@hotmail.com)

Received: 20 November 2017, Revised: 19 June 2018, Accepted: 30 July 2018

\begin{abstract}
Physic nut (Jatropha curcas L.), a promising alternative resource for biodiesel production, produces restrictively a seed yield and has a low level of genetic variation, causing a barrier to improve the oil performance. Therefore, better understanding of reproductive biology is crucially important for breeding programs to achieve commercial viability in the future. The developmental features related to floral bud diameter and floral morphology of male and female gametophytes, by means of light and scanning electron microscopes, and their capability were investigated. It was found that bud diameter could be used as criteria for identification of pollen and embryo sac stages. Pollen capability and stigma receptivity showed an inverse S-shape with time after flowering. The highest pollen viability assessed by FCR (93.20 - $98.60 \%)$, TTC $(78.80-87.00 \%)$, and germination test $(43.40 \%)$ were obtained at $0-8,0-12$, and 0 HAF, respectively. Moderately linear correlations were exhibited between viability and germination test $\left(\mathrm{R}^{2}=0.57-0.62\right)$. Stigma receptivity was the highest $(97.22-100 \%)$ on the first three days.
\end{abstract}

Keywords: Pollen viability, Embryo sac, Bud diameter, Stigma receptivity, Biodiesel

\section{Introduction}

Physic nut (Jatropha curcas L., Euphorbiaceae) is a shrub tree, up to $6-15 \mathrm{~m}$ high, native to tropical America and now vastly grown in tropical regions, such as Africa and Asia $[1,2]$. This species is deciduous and can survive in arid and semi-arid areas. It is a monoecious plant which produces female and male flowers in the same inflorescence at the branch terminal [3]. The flowering and fruiting periods take place during the wet season (late summer to early fall) [2,4]. This species is an attractive source for biodiesel production due to its inedible oil and fatty acid composition, which is analogous to that of fossil fuel [4]. The lipid mainly consists of high oleic $(44.7 \%)$, linoleic $(32.8 \%)$, palmitic $(14.2 \%)$ and stearic acid $(7.0 \%$ ) [5]. The high proportion of oleic acid will provide biodiesel with good general properties exhibiting the combination of high cetane number and low cold filter plugging point [6]. However, the full potential of Jatropha has not been achieved due to its variety restriction, leading to the limitation of desired traits and lack of high oil yielding variety [4,7]. Thus, a production of variety with improved quality via breeding programs is essential for this plant. Accordingly, haploid and double haploid embryos are required, because they provide homozygous genotypes necessary for breeding programs [8]. Haploid embryos can be induced through anther [9] or unfertilized eggs [8]. An appropriate stage of microspore and embryo sac, which is one of the most critical parameters for the success of the haploid culture, varies among the species [8,10,11]. Thus, the sequentially developmental events of male and female gametophytes relating to floral features of this plant are prioritized information for bud selection at the accurate stages required for such cultures. Moreover, the longevity of pollen and stigma fertility is still limited in this species. Pollen and stigma at high capability periods are demanded for the pollination 
http://wjst.wu.ac.th

set to ensure fruit and seed fecundity $[12,13]$. Cytochemical staining, including fluorochromatic reaction (FCR) and 2, 3, 5 - triphenyl tetrazolium chloride (TTC), has been widely used to evaluate pollen viability by checking enzymatic activity and membrane integrity [14,15]. Germination assay has also been extensively employed to define the true ability of pollen to germinate under in vitro conditions [16]. Meanwhile, checking of stigmatic peroxidase activity with hydrogen peroxide is common for pistil receptivity testing $[17,18]$. Hence, this research aimed to determine (i) the development of pollen and embryo sac in relation to floral bud diameter and morphology and (ii) the longevity of pollen and stigma fertility. The information can be utilized for selecting proper flower stages required for the development of haploid plants via anther and ovary/ovule culture, as well as for pollination manipulation, which are essential for oil-yielding improvement programs of $J$. curcas L.

\section{Materials and methods}

\section{Plant materials}

Local $J$. curcas plants grown in sandy loam soil at Trang Agricultural Occupation Promotion and Development Center (TAOPDC), Trang Province, Thailand, were used as materials and kept as voucher specimens (Nuanjunkong 01) in the international herbarium-PSU (Department of Biology, Faculty of Science, Prince of Songkla University). At the plantation, the total rain was 2,266.20 mm, and the average temperature was $28.80^{\circ} \mathrm{C}$. All experiments were carried out during 2013 - 2014 at TAOPDC and Prince of Songkla University, Songkhla, Thailand.

\section{General flower characteristics and gametophyte development}

Male and female flower buds were randomly collected at $8.00-9.00 \mathrm{a} . \mathrm{m}$. from five individual plants. These buds were measured and divided into 5 groups $(1.0-1.5,1.6-2.0,2.1-3.0,3.1-4.0$, and $>$ $4.0 \mathrm{~mm}$ ) based on diameter. For each group, morphological appearances of floral organs were recorded on at least six sampling buds and, were photographed using an Olympus SZH 10 stereomicroscope joined to a DP-71 digital camera. The samples were then fixed in FAA II (70 \% ethanol: glacial acetic acid: formalin, 90: 5: 5) for $48 \mathrm{~h}$, dehydrated in a series of tert-butyl alcohol, embedded in Paraplast Plus, and cut at $6 \mu \mathrm{m}$ thickness using a rotary microtome. The sections were stained with hematoxylin and safranin for histological features, and with $0.1 \%(\mathrm{w} / \mathrm{v})$ aniline blue for callose wall observation [19]. In the latter case, fluorescent images were taken under excitation wavelength at $365 \mathrm{~nm}$ using an Olympus-BX51 microscope. Pollen surface was determined using a SEM-Quanta scanning electron microscope at $20 \mathrm{kV}$. The ratio of male to female flowers was estimated from 40 inflorescences.

\section{Pollen assessment via FCR, TTC and germination test}

Inflorescences with nearly bloomed male flowers were collected, placed in $250 \mathrm{ml}$ beakers filled with $200 \mathrm{ml}$ tap water, and maintained at room temperature $\left(25 \pm 3{ }^{\circ} \mathrm{C}\right)$ overnight [15]. The tests were performed on pollen collected from those inflorescences at 0 (anthesis time, 8.00 a.m.), 4, 8, 12, 24, 48, 72 , and $96 \mathrm{~h}$ after flowering (HAF). For the FCR test, the pollen was transferred to a mixture of $15 \%$ sucrose and fluorescein diacetate (FDA) solution, followed by $10 \mathrm{~min}$ incubation in a humidity chamber. Bright yellow-green pollen under the fluorescence microscope, with an excitation wavelength at $489 \mathrm{~nm}$, were scored as viable [20]. For the TTC test, pollen was stained with $1 \%$ TTC solution and kept in darkness for $24 \mathrm{~h}$, then washed thrice with distilled water. Red-stained pollen was considered viable [15]. In vitro germination was performed according to the published protocol [16]. Briefly, the pollen was released into depression slides filled with $20 \mu \mathrm{L}$ of Brewbaker \& Kwack (BK) liquid medium [21] supplemented with $20 \%$ sucrose, $2.5 \%$ coconut water and $10 \%$ polyethylene glycol (PEG 4000) at pH 6.5. The culture media were placed in a moist chamber and kept at $25 \pm 3{ }^{\circ} \mathrm{C}$ in darkness for $14 \mathrm{~h}$. The pollen whose tube reached greater length than its own diameters was considered germinated. For all experiments, pollen autoclaved at $15 \mathrm{psi}$ at $121{ }^{\circ} \mathrm{C}$ for $20 \mathrm{~min}$ was simultaneously used as a negative control. Percentages of viability and germination were determined from 5 replicates, each consisting of 100 pollen specimens. Data were submitted to the Kruskal-Wallis test at a $5 \%$ probability level $(P \leq$ 0.05) available on portable IBM SPSS Statistics, version 19. Linear correlations between the pollen 
http://wjst.wu.ac.th

staining techniques and the germination test were carried out using simple linear regression analysis on the SPSS.

\section{Stigma receptivity}

The female flowers were bagged before flowering, and the receptivity of stigmata tested with $3 \%$ hydrogen peroxide solution was accomplished at 0 (at flowering time, 8.00 a.m.), 1, 2, 3, 4, 5, and 6 days after flowering (DAF). Stigmata having oxygen bubbles within 2 to 3 min were considered receptive [17]. The percentage of receptive stigmata was calculated using 3 replications, each with 12 stigmata. The Kruskal-Wallis test was used in order to analyze significant differences of means.

\section{Results and discussion}

\section{Morphological characteristics of male and female flowers}

Physic nut produces both male and female flowers on the same cymose inflorescence. The innermost female flower, located at the center, is surrounded by male flowers (Figure 1A). In Brazil and China, Jatropha inflorescences were classified into corymbose cyme [22] and dichasial cyme [23], respectively. This study showed the number of female flowers was lower than that of male flowers representing a male to female ratio of 17: 1 per inflorescence. A sex ratio (male: female) ranged from 13:1 to 108:1 was reported for this species, as mentioned by Fresnedo-Ramírez [24]. These fewer female flowers resulted in low seed set and low oil productivity in this plant [23]. Male flowers, with round heads and thin pedicels (Figure 1B), have five greenish-yellow sepals and five greenish-yellow petals enriched with hairs (Figure 1C). There are five globular nectaries at the base of the filaments. These nectaries are initially greenish in color and change to yellow at anthesis (Figure 1C). The male flower contains 10 stamens arranged in 2 whorls; free outer and fused inner whorls (Figure 1C). The anther is bilobed (with four pollen sacs), extrorse type (dehisces longitudinally outward) and joins to filament by subbasifixed attachment (Figure 1D). Differently, dorsifixed and basifixed attachments were observed by other authors for this species [22, 23]. The female flower has conical apex and thick pedicel (Figure 1E). It has five greenish-yellow sepals and five greenish-yellow petals with plentiful hairs (Figure 1F) which are similar to those of the male flower. Flattened and ovate nectaries (five in number), presenting yellow color during the anthesis, are arranged at the base of the ovary (Figure 1F). The ovary, with 3 fused carpels, is comprised of 3 locules, each with one ovule exhibiting apical placentation (Figures 1F and 1G). On the connate style rests three bifurcated stigmata (Figures 1F and 1H). Noticeably, sterile stamens showing abnormal-shaped anthers without filament are observed at the base of the ovary, both at early (1.0 - $2.0 \mathrm{~mm}$ bud diameter) (Figure 1H) and late $(\geq 2.1 \mathrm{~mm}$ bud diameter) (Figure 1I) stages of female flower development. Traces of stamens, containing no mature pollen and lacking pollination capability, are also detected in female flowers of physic nuts grown in Brazil [23]. 

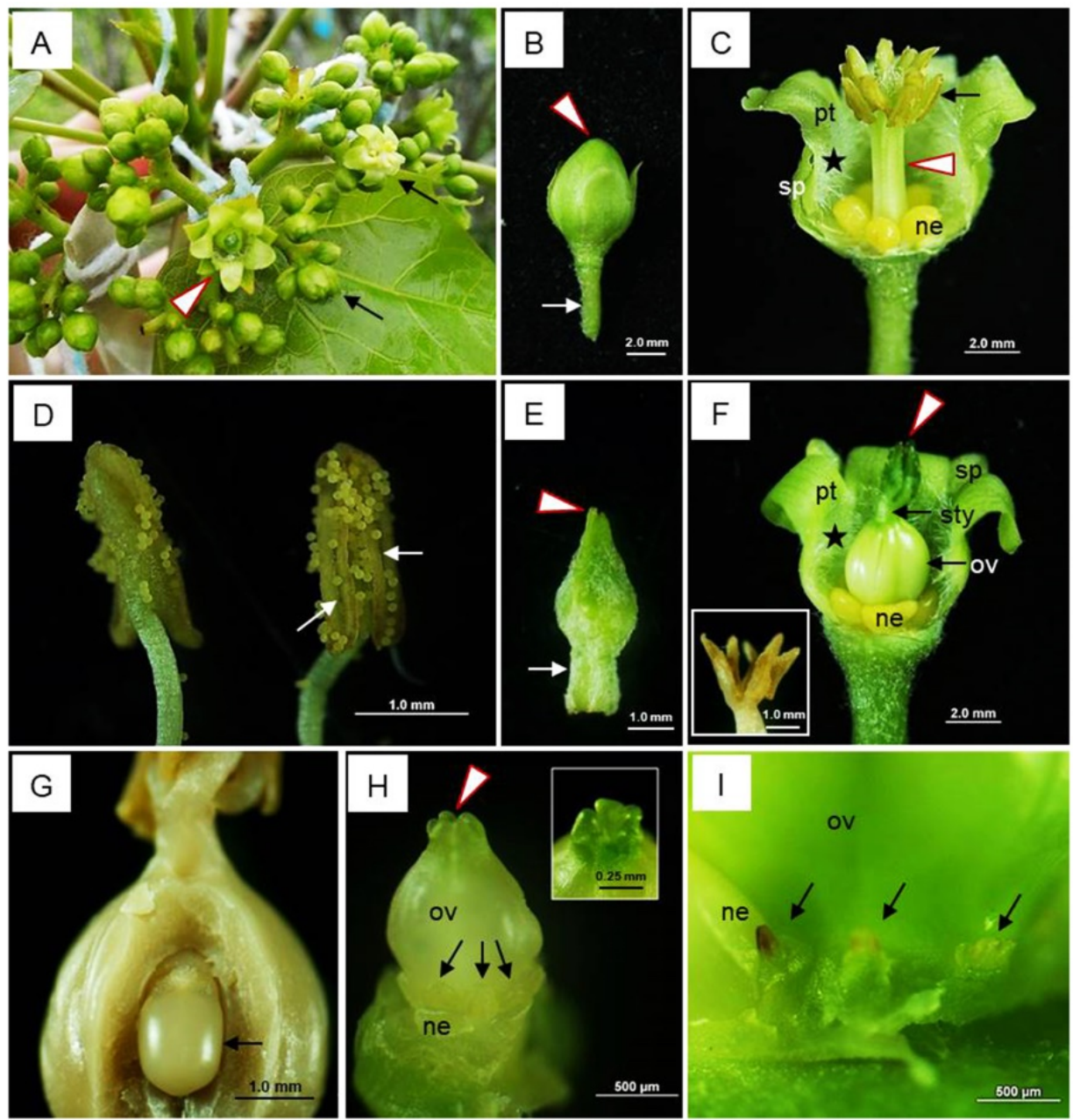

Figure 1 Floral morphology of Jatropha curcas L. (A) Cymose inflorescence presenting male (arrows) and female flowers (arrowhead); (B) Male flower showing a round head (arrowhead) with thin pedicel (arrow); (C) Dissected male flower showing sepal (sp), petal (pt) covered with hair ( $\star$ ), round nectary gland (ne), filament (arrowhead), and anther (arrow); (D) Stamens illustrating longitudinal slits of anther at shedding period (arrows); (E) Female flower with conical head (arrowhead) and thick pedicel (arrow); (F) Dissected female flower exhibiting sepal (sp), petal (pt) with hair ( $\star$ ), flattened and ovate nectary (ne), ovary (ov), style (sty), and three bifurcate stigma (arrowhead and inset); (G) Ovary with an ovule (arrow); (H) Sterile stamens (arrows) and developing stigma (arrowhead and inset) at early development of female flower; (I) Sterile stamens (arrows) at near-bloom period of female flower. ne, nectary; ov, ovary; pt, petal; sp, sepal; sty, style.

\section{Male and female gametophyte development in relation to bud diameter and morphology \\ Male gametophyte (pollen) development}

The anther contains 4 locules (Figure 3A) whose wall layers, namely, the outermost epidermis, endothecium, middle layer, and the innermost tapetum, are observed. Male gametophyte development could be indicated as the stages of (a) pollen mother cell (PMC), (b) microspore tetrad, (c) uninucleate microspore, (d) early binucleate pollen with globular-shaped generative cell, and (e) late binucleate pollen with spindle-shaped generative cell at the flower bud sizes of $1.0-1.5,1.0-1.5,1.6-2.0,2.1-3.0$, and $\geq$ 
http://wjst.wu.ac.th

$3.1 \mathrm{~mm}$ in diameter, respectively. Firstly, the flower bud (1.0 - $1.5 \mathrm{~mm}$ in diameter) having a clump of anthers with undeveloped filament and nectary (Figure 2A), displays both stages of PMC (Figure 3B) and tetrahedral tetrad (Figure 3C). At this flower size, the degrading middle layer of anther walls (Figures 3B and 3C) and the callose wall deposition around tetrad microspores (Figure 3D) could be noticed. Secondly, most of the flower buds at $1.6-2.0 \mathrm{~mm}$ are in the stage of uninucleate microspore presenting the exine layer (Figure 3E). Flower bud also presents a cluster of anthers with undeveloped filament and nectary gland (Figure 2A). The degenerated middle layer is presented while epidermis, endothecium, and tapetum are still clearly visualized (Figure 3E). Finally, bud size of about $\geq 2.1 \mathrm{~mm}$ exhibits binucleate pollen stage. Flower bud $(2.1-3.0 \mathrm{~mm})$ possesses developing filament which is hidden by the presence of small greenish nectaries (Figure 2A). The anther wall is composed of the epidermal layer, the fibrous endothecium, the collapsing tapetum, and the degraded middle layer (Figure 3F). For this size, the majority of buds are at early binucleate mature pollen containing the vegetative nucleus (Figure 3F, arrowhead) and the globular-shaped generative cell detached from pollen wall (Figure 3F, gn). Then, the bud $(\geq 3.1 \mathrm{~mm}$ ) with elongated filaments and developed nectaries (Figure 2A) presents a spheroidal pollen $(76.72 \pm 1.17 \mu \mathrm{m}$ in diameter) containing the vegetative nucleus (Figure 3G, vg) and the spindle-shaped generative cell (Figure 3G, arrowhead). At this stage, the layers of the epidermis and the fibrous endothecium still remain (Figure 3G). At anthesis, pollen is shed at a twocelled stage (Figure 3H) and presents surface clavae arranged in a crotonoid pattern (polygonal alignment) (Figure 3I). Observation of the stages of PMC and tetrad in the same bud size of different flowers was possible in this study because the PMC undergoes meiosis rapidly and develops to form a tetrad faster than the enlargement of flower bud. Liu et al. [25] illustrated that the PMC, tetrad, free microspore, and binucleated pollen of physic nut could be detected at the anther lengths of $0.5-0.7,0.7$ $0.78,0.83-1.0$, and $1.7-2.2 \mathrm{~mm}$, respectively. Thus, a rapid selection, by roughly scanning the developmental stage using flower bud diameter (this study), was prerequisite, and then the anther length provided by Liu et al. [25] could be used to classify the stages between PMC and tetrad. The occurrence of nectary and filament could be used to separate gametogenesis from sporogenesis in this study. However, both sporogenesis and gametogenesis of Arabidopsis thaliana were observed in flower buds exhibiting visual filament [26]. Using buds whose size correlated to a suitable stage of pollen development has been one of the crucial factors determining the success of in vitro microspore or anther culture [10], and different stages were required for different species [9,11]. Hence, flower buds of $\geq 1.6$ $\mathrm{mm}$ in diameter presenting haploid unicellular microspore or bicellular pollen might be suitable and recommended for the haploid plant induction of $J$. curcas.

\section{Female gametophyte (embryo sac) development}

The anatropous bitegmic and crassinucellate ovule is observed (Figure 4A) and the embryo sac is of monosporic polygonum type (Figures 4B - 4N) which corresponds with and confirms the study mentioned by Krishnamurthy [27] for the same species. The female bud $(1.0-1.5 \mathrm{~mm})$ presents the initiation of style and stigma, a large sterile stamen, and a small nectary gland (Figure 2B). Megaspore mother cell (MMC) displaying a large nucleus with dense cytoplasm is deeply embedded within a massive nucellus (Figures 4A and 4B). The anatomical feature confirms that the stamens found in female flowers are sterile by having locule shrinkage without PMC at this MMC stage (Figures 4C and 4D), indicating these sterile stamens might have no impact on any pollination sets. This study supports a previous report, which observed the restrained stamen in the female flower of physic nut grown in China [28]. The sterile stamen was also observed evidently in the female flowers of relative species such as $J$. multifida and $J$. integerrima [29]. The bud size of $1.6-2.0 \mathrm{~mm}$ possesses developing style and stigma (Figure 2B), while the sterile stamens remained larger than the nectaries. The linear arrangement of four haploid megaspores (Figure 4E), resulting from meiosis of MMC, is noticed at this flower size. A haploid megaspore located at the chalazal end survives, while three of these megaspores at the micropylar region are degenerated (Figure 4E). The functional megaspore (Figure 4F, inset) undergoes mitosis to produce binucleate embryo sac (Figure 4G), and subsequently develops to multinucleate immature embryo sac (Figure 4H). The stage of eight-nucleate embryo sac is mostly found in the bud ( $\geq 2.1 \mathrm{~mm})$, 
http://wjst.wu.ac.th

whose developed style, stigma, and larger nectaries covering sterile stamens are presented (Figure 2B). The bud of $2.1-4.0 \mathrm{~mm}$, displaying the white nectaries (Figure 2B), contains immature 8-nucleate embryo sac, in which the migration of two polar nuclei to the center is not yet completed (Figures 4I 4K), whereas the buds $(>4 \mathrm{~mm}$ ) having yellow nectaries possess mature 8-nucleate embryo sac comprised of antipodal cells (Figure 4L), egg cell, and synergids (Figure 4M) and two juxtaposed polar nuclei at the center (Figures 4M - 4N). The floral diameter related to the stage of embryo sac has also been established in onion (Allium cepa) [30]. A suitable stage of ovule for haploid and dihaploid production varied depending on species was considered, ranging from the stage of megaspore to mature embryo sac [8]. Consequently, for $J$. curcas, haploid and double haploid induction would begin by using ovules from $\geq 1.6 \mathrm{~mm}$ buds, which contain haploid megaspore to mature embryo sac, to find the most responsive stage of embryo sac on the culture.

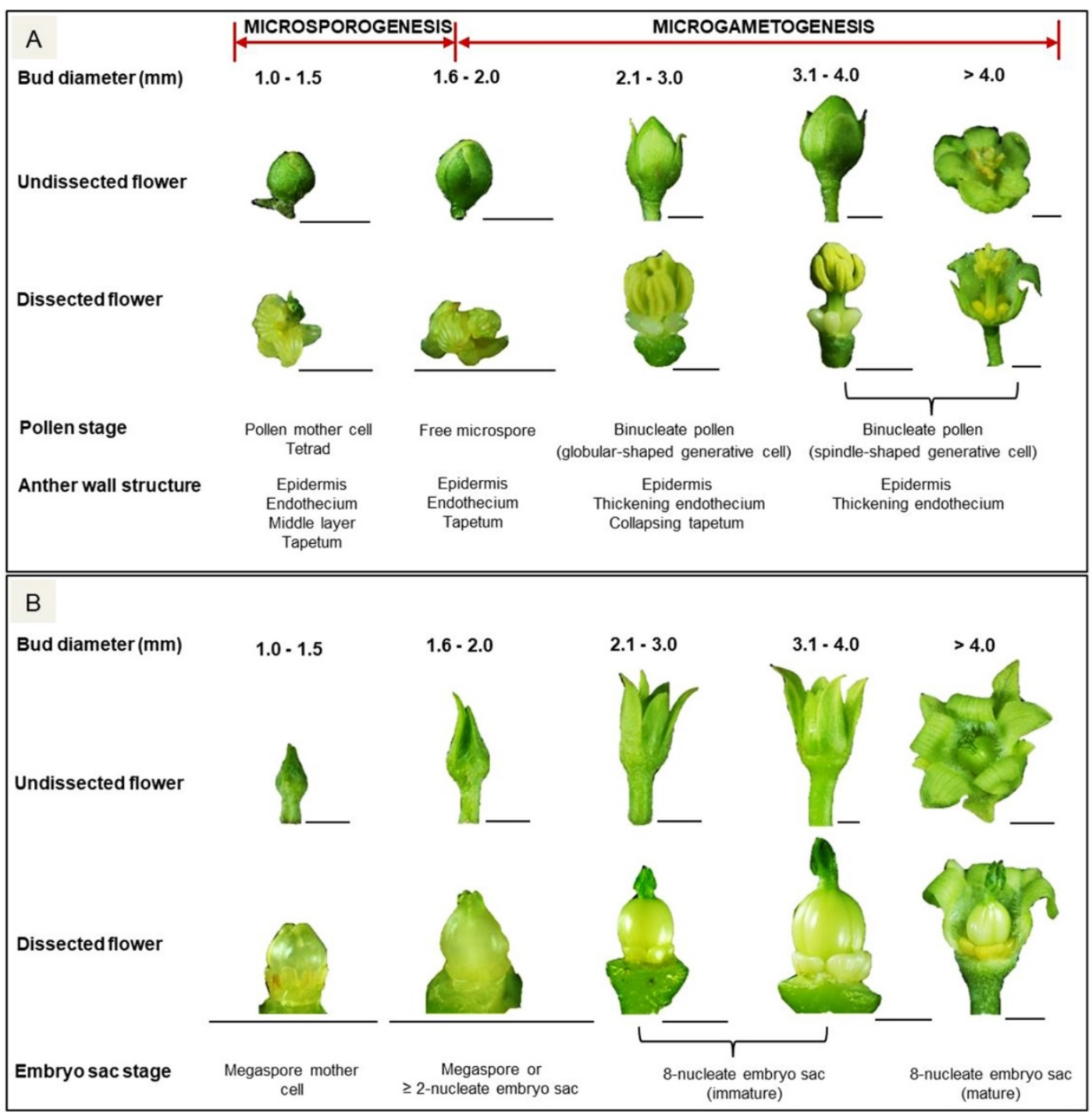

Figure 2 Summarized correlation between flower bud diameter, morphology, and developmental events of Jatropha curcas L. in (A) male and (B) female flowers. Scale bar $=2 \mathrm{~mm}$ 
http://wjst.wu.ac.th

Therefore, flower buds exhibiting the proper stage of pollen and embryo sac could be chosen for in vitro haploid and dihaploid production required for breeding programs to produce new plant cultivar with higher oil yielding. To reduce the biodiesel price and have economic competitiveness, the obtained cultivar should contain oil higher than the $37-50 \%$ derived from the rapeseed (Brassica napus), the main feedstock of the world biodiesel production [31].
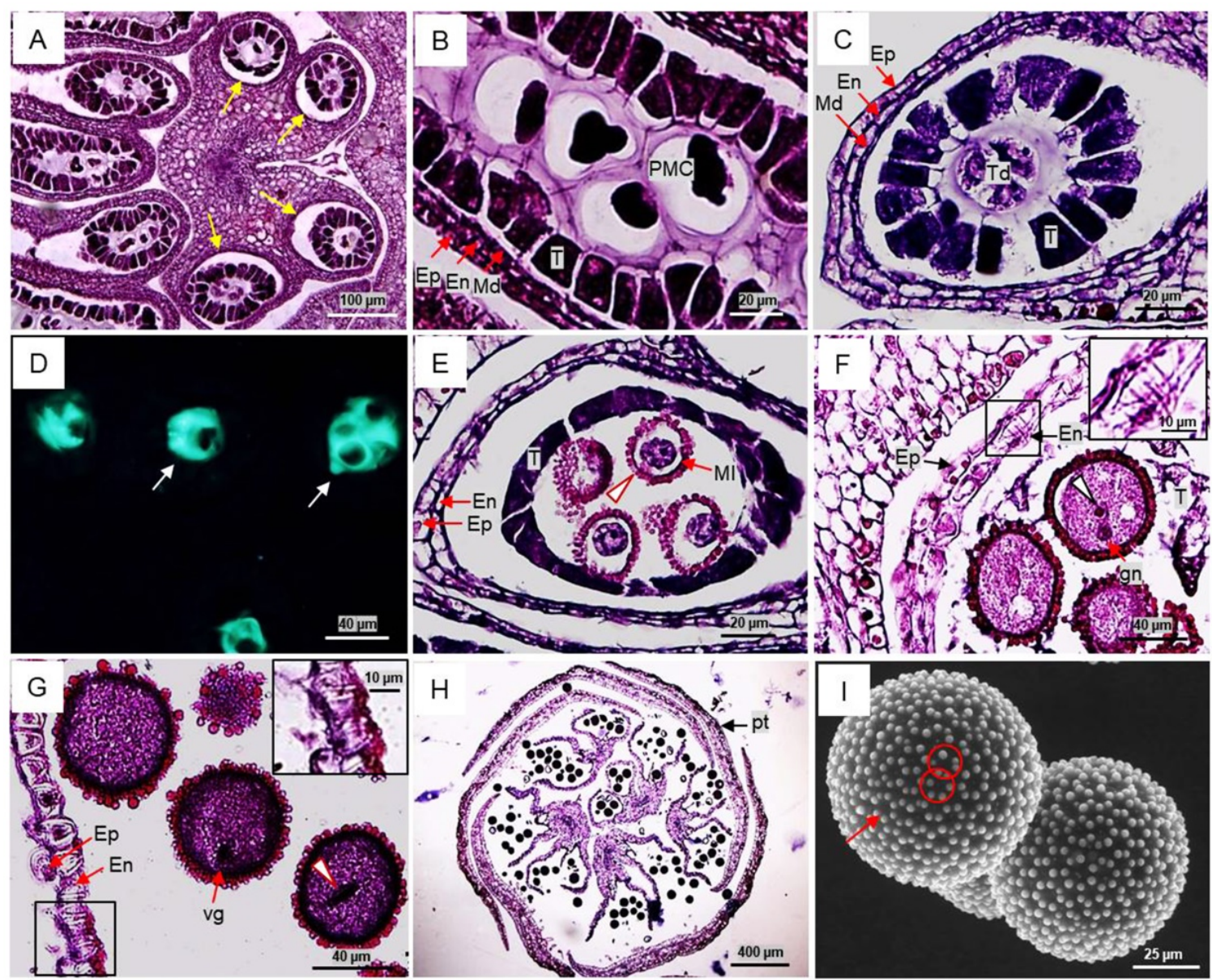

Figure 3 Pollen development of Jatropha curcas L. (A) Anther with four locules (arrows); (B) PMC with large nucleus and all anther walls including epidermis (Ep), endothecium (En), middle layer (Md), and tapetum (T); (C) Tetrad (Td) and all anther wall layers; (D) Callose wall (arrows) surrounding the tetrad microspores after aniline blue fluorescence; (E) Free microspore (MI) displaying the exine wall (arrowhead); (F) Binucleate pollen showing small and dense vegetative nucleus (arrowhead) and a globular-shaped generative cell (gn). Insets illustrating the fibrous thickening of the endothecium; (G) Mature pollen containing the vegetative nucleus (vg) and the spindle-shaped generative cell (arrowhead). Insets showing thicker and more fibrous wall of endothelial cells; $(\mathrm{H})$ Pollen releasing from anther before the opening of petal (pt); (I) SEM micrograph exhibiting mature pollen with clavae (arrow) arranging as croton pattern (circles); En, endothecium; Ep, epidermis; gn, generative cell; Md, middle layer; MI, microspore; PMC, pollen mother cell; pt, petal; T, tapetum; Td, tetrad microspore; vg, vegetative nucleus. 



Figure 4 Longitudinal sections of Jatropha curcas L. female flowers determining embryo sac development. (A) Anatropous ovule with MMC (arrow), nucellus (n), inner integument (ii) and outer integument (oi); (B) MMC; (C) Sterile stamens (arrows) at MMC stage; (D) Amplification of inset in (C) showing sterile stamen with shrinkage locule (arrow); (E) Three degenerating megaspores (arrows) at micropylar and a survival megaspore (arrowhead) at chalazal pole; (F) Ovule at megaspore stage presenting caruncle (cr), nucellus (arrow), inner integument (ii) and outer integument (oi). Insets show a functional megaspore; (G) Binucleate embryo sac; (H) Multinucleate embryo sac; (I - K) Serial section of immature embryo sac indicating (I) Presumptive egg apparatus (arrows) and polar nucleus (arrowhead); (J) The same sample as (I) in deeper section, showing presumptive egg apparatus (arrow); (K) In other plane, representing presumptive antipodal cells (arrows); (L - N) Mature embryo sac showing (L) Antipodal cells (arrows); (M) Central polar nucleus (arrowhead), egg cell (arrow), and synergids ( $\star$ ); (N) Consecutive plane of (M), showing another polar nucleus (arrowhead) and egg cell (arrow). cr, caruncle; ii, inner integument; MMC, megaspore mother cell; n, nucellus; ne, nectary; oi, outer integument; ov, ovary.

\section{Pollen capability and stigma receptivity}

The viable pollen exhibited yellow-green fluorescence (Figure 5A), red color (Figure 5B), and germinated tube (Figure 5C) after FCR, TTC, and germination test, respectively. All techniques employed in pollen capability test, exhibiting inverse S-shape, displayed the reduction of pollen capability along the time course after flowering (Figure 5E). From the FCR result, the highest viability was found at $4 \mathrm{HAF}(98.60 \%)$ and not significantly different from $95.80 \%$ at $0 \mathrm{HAF}$ and $93.20 \%$ at $8 \mathrm{HAF}$. The 
http://wjst.wu.ac.th

viability dropped sharply from $86.60 \%$ at $24 \mathrm{HAF}$ to the lowest $(31.40 \%)$ at $96 \mathrm{HAF}$. By TTC, the maximal viability was $87.00 \%$ at the flowering time, which was not significantly different from 4,8 and 12 HAF. The viability decreased markedly (66.60 - 21.60\%) during 24 to $48 \mathrm{HAF}$, and the lowest (15\%) was shown at $72 \mathrm{HAF}$. The highest germination $(43.40 \%)$ was observed at the flowering time. Then, the germination frequency exceedingly dropped to $19.60 \%$ (at 4 HAF) and to $2.20 \%$ (at 96 HAF). The results showed that TTC $\left(\mathrm{R}^{2}=0.6205\right)$, rather than FCR $\left(\mathrm{R}^{2}=0.5686\right)$, was slightly more correlated with the germination test, based on the linear pattern (Figure 5F). TTC test was more effective for the evaluation of pollen viability than FCR for this plant [15]. Accordingly, pollen capability of physic nut should be considered from TTC and germination results, which showed the highest viability of $87.00 \%$ and germination of $43.40 \%$ at the flowering time. Previous reports displayed physic nut pollens were viable at $95.4 \%$ by TTC and were germinated at 30 to $71.6 \%[15,16]$. The viability was at its peak at $9 \mathrm{~h}$ after blooming [32]. The difference might be attributed to the species genotype and growth environment $[33,34]$. TTC was also reliable for Leymus chinensis [35] and Kochia scoparia [36], but not for Festuca arundinacea, in which viable and dead pollen showed the same color after staining [33]. The receptive stigma represented the number of bubbles at the stigmatic apex (Figure 5D, arrows) and illustrated the inverse S-shape longevity (Figure 5G). Receptivity displayed the maximal value at $100 \%$ during a period of $0-2 \mathrm{DAF}, 97.22 \%$ at $3 \mathrm{DAF}$, and steadily decreased to the lowest $(36.11 \%)$ at 6 DAF. This relatively concurs with an earlier report mentioning that the physic nut stigma could be receptive for around the first 4 days and began to decline at the fifth day [32].



Figure 5 Pollen capability and stigma receptivity of Jatropha curcas L. (A) Bright fluorescence of viable pollen after FCR test; (B) Red viable pollen (arrows) after TTC test; (C) Germinated pollen tube (arrow); (D) Released bubbles (arrows) indicating receptive stigma by hydrogen peroxide test; (E) Viability (by TTC and FCR tests) and germination percentage of pollen showing inverse S-shape pattern; (F) A linear relationship between pollen viability and germination; (G) Stigma receptivity showing inverse S-shape longevity. Different letters in each line indicate significant differences at $P \leq 0.05$. 
http://wjst.wu.ac.th

\section{Conclusions}

The study described the relationship between flower bud diameter and the developmental stages of both pollen and embryo sac in physic nut. Floral buds of $1.6 \mathrm{~mm}$ in diameter onwards, which highly related to haploid microspore to binucleate pollen for male flowers and haploid megaspore to mature embryo sac for female flowers, would be employed for haploid production. Pollens collected at blooming and stigmata at 0 - 3 DAF, displaying high capability, should be applied in artificial pollination and breeding programs.

\section{Acknowledgments}

The authors are grateful to the Graduate School, Prince of Songkla University, for research funding and the scholarship for the support of exchange students and international credit transferred through the ASEAN Community. We are thankful to the Science Achievement Scholarship of Thailand (SAST) for the doctoral scholarship. We wish to thank the TAOPDC for their generous permission to employ $J$. curcas plantation. We also acknowledge Mrs. Anna Chatthong from the Faculty of Science, Prince of Songkla University, for assistance with the English in the manuscript.

\section{References}

[1] PC Van Welzen and K Chayamarit. Flora of Thailand. Vol. 8. Part 2, Euphorbiaceae (Genera G-Z). The Forest Herbarium, National Park, Wildlife and Plant Conservation Department, Bangkok, 2007, p. 305-592.

[2] GA Levin and L Gillespie. Euphorbiaceae. In: Flora of North America Editorial Committee (Eds.). Flora of North America North of Mexico Volume 12. Oxford University Press, New York, 2016, p. 156-324.

[3] LAS Dias, RF Missio and DCFS Dias. Antiquity, botany, origin and domestication of Jatropha curcas (Euphorbiaceae), a plant species with potential for biodiesel production. Genet. Mol. Res. 2012; 11, 2719-28.

[4] BN Divakara, HD Upadhyaya, SP Wani and CLL Gowda. Biology and genetic improvement of Jatropha curcas L.: A review. Appl. Energ. 2010; 87, 732-42.

[5] E Akbar, Z Yaakob, SK Kamarudin, M Ismail and J Salimon. Characteristic and composition of Jatropha curcas oil seed from Malaysia and its potential as biodiesel feedstock. Eur. J. Sci. Res. 2009; 29, 396-403.

[6] MJ Ramos, CM Fernandez, A Casas, L Rodriguez and A Perez. Influence of fatty acid composition of raw materials on biodiesel properties. Bioresource Technol. 2009; 100, 261-8.

[7] DG Ambrosi, G Galla, M Purelli, T Barbi, A Fabbri, S Lucretti, TF Sharbel and G Barcaccia. DNA markers and FCSS analyses shed light on the genetic diversity and reproductive strategy of Jatropha curcas L. Diversity 2010; 2, 810-36.

[8] JF Chen, L Cui, AA Malik and KG Mbira. In vitro haploid and dihaploid production via unfertilized ovule culture. Plant Cell Tissue Organ. Cult. 2011; 104, 311-9.

[9] D Grauda, K Žagata, G Lanka, V Strazdina, V Fetere, N Lisina, N Krasnevska, O Fokina, A Mikelsone, R Ornicans, I Belogrudova and I Rashal. Genetic diversity of wheat (Triticum aestivum L.) plants: Regenerants produced by anther culture. Vavilovskii Zhurnal Genet Selektsii 2016; 20, 537-44.

[10] MDS Lauxen, EK Santos, CY Hu, SMC Jacques and MHB Zanettini. Association between floral bud size and developmental stage in soybean microspores. Braz. Arch. Biol. Tech. 2003; 46, 515-20.

[11] MR Malik, F Wang, JM Dirpaul, N Zhou, PL Polowick, AMR Ferrie and JE Krochko. Transcript profiling and identification of molecular markers for early microspore embryogenesis in Brassica napus. Plant Physiol. 2007; 144, 134-54.

[12] JL Stone, JD Thomson and SJD Acosta. Assessment of pollen viability in hand-pollination experiments: a review. Am. J. Bot. 1995; 82, 1186-97. 
http://wjst.wu.ac.th

[13] A Hedhly, JI Hormaza and M Herrero. The effect of temperature on stigmatic receptivity in sweet cherry (Prunus avium L.). Plant Cell Environ. 2003; 26, 1673-80.

[14] DH Lyra, LS Sampaio, DA Pereira, AP Silva and CLF Amaral. Pollen viability and germination in Jatropha ribifolia and Jatropha mollissima (Euphorbiaceae): Species with potential for biofuel production. Afr. J. Biotechnol. 2011; 10,368-74.

[15] HA Abdelgadir, SD Johnson and JV Staden. Pollen viability, pollen germination and pollen tube growth in the biofuel seed crop Jatropha curcas (Euphorbiaceae). South Afr. J. Bot. 2012; 79, 1329.

[16] $\mathrm{C} \mathrm{Li}, \mathrm{M} \mathrm{Yu}, \mathrm{F}$ Chen and $\mathrm{S}$ Wang. In vitro maturation and germination of Jatropha curcas microspores. Int. J. Agric. Biol. 2010; 12, 541-6.

[17] A Lankinen, WS Armbruster and L Antonsen. Delayed stigma receptivity in Collinsia heterophylla (Plantaginaceae): genetic variation and adaptive significance in relation to pollen competition, delayed self-pollination, and mating-system evolution. Am. J. Bot. 2007; 94, 1183-92.

[18] LAS Pio, JD Ramos, M Pasqual, FC Santos and KP Junqueira. Receptiveness of the stigma and in vitro germination of orange pollen, submitted to different temperatures. Ciênc. Agrotec. 2004; 28, 1087-1091.

[19] SE Ruzin. Plant Microtechnique and Microscopy. Oxford University Press, New York, 1999, p. 1322.

[20] DVD Walt and GM Littlejohn. Storage and viability testing of Protea pollen. J. Am. Soc. Hort. Sci. 1996; 121, 804-9.

[21] JL Brewbaker and BH Kwack. The essential role of calcium ion in pollen germination and pollen tube growth. Am. J. Bot. 1963; 50, 859-65.

[22] BG Brasileiro, DCFS Dias, MC Bhering and LAS Dias. Floral biology characterization of seed germination in physic nut (Jatropha curcas L.). Rev. Bras. Sem. 2012; 34, 556-62.

[23] XR Wang and GJ Ding. Reproductive biology characteristic of Jatropha curcas (Euphorbiaceae). Rev. Biol. Trop. 2012; 60, 1525-33.

[24] J Fresnedo-Ramírez. The floral biology of Jatropha curcas L.: A review. Trop. Plant Biol. 2013; 6, $1-15$.

[25] H Liu, BK Kirchoff, G Wu and J Liao. Microsporogenesis and male gametogenesis in Jatropha curcas L. (Euphorbiaceae). J. Torrey Bot. Soc. 2007; 134, 335-43.

[26] M Cardarelli and V Cecchetti. Auxin polar transport in stamen formation and development: How many actors? Front. Plant Sci. 2014; 5, 1-13.

[27] KV Krishnamurthy. Embryology of Jatropha: A Review. In: B Bahadur, M Sujatha and N Carels (Eds.). Jatropha, Challenges for a New Energy Crop: Volume 2: Genetic Improvement and Biotechnology. Springer Science+Business Media New York, 2013, p. 75-86.

[28] J Wu, Y Liu, L Tang, F Zhang and F Chen. A study on structural features in early flower development of Jatropha curcas L. and the classification of its inflorescences. Afr. J. Agric. Res. $2011 ; 6,275-84$.

[29] H Liu, S Lin and J Liao. Floral ontogeny of two Jatropha species (Euphorbiaceae S.S) and its systematic implications. Pak. J. Bot. 2015; 47, 959-65.

[30] K Musial, B Bohanec, M JakŠe and L Przywara. The development of onion (Allium cepa L.) embryo sacs in vitro and gynogenesis induction in relation to flower size. In Vitro Cell Dev. Biol. Plant 2005; 41, 446-52.

[31] MM Gui, KT Lee and S Bhatia. Feasibility of edible oil vs. non-edible oil vs. waste edible oil as biodiesel feedstock. Energy 2008; 33, 1646-53.

[32] L Change-Wei, L Kun, C You, S Yong-Yu and Y Wen-Yun. Pollen viability, stigma receptivity and reproductive features of Jatropha curcas L. (Euphorbiaceae). Acta Bot. Boreali-Occidential Sinica 2007; 10, 1994-2001.

[33] ZY Wang, Y Ge, M Scott and G Spangenberg. Viability and longevity of pollen from transgenic and nontransgenic tall fescue (Festuca arundinacea) (Poaceae) plants. Am. J. Bot. 2004; 91, 523-30.

[34] A Hedhly, JI Hormaza and M Herrero. Influence of genotype-temperature interaction on pollen performance. J. Evol. Biol. 2005; 18, 1494-502. 
http://wjst.wu.ac.th

[35] Z Huang, J Zhu, X Mu and J Lin. Pollen dispersion, pollen viability and pistil receptivity in Leymus chinensis. Ann. Bot. 2004; 93, 295-301.

[36] D Mulugeta, BD Maxwell, PK Fay and WE Dyer. Kochia (Kochia scoparia) pollen dispersion, viability and germination. Weed Sci. 1994; 42, 548-52. 